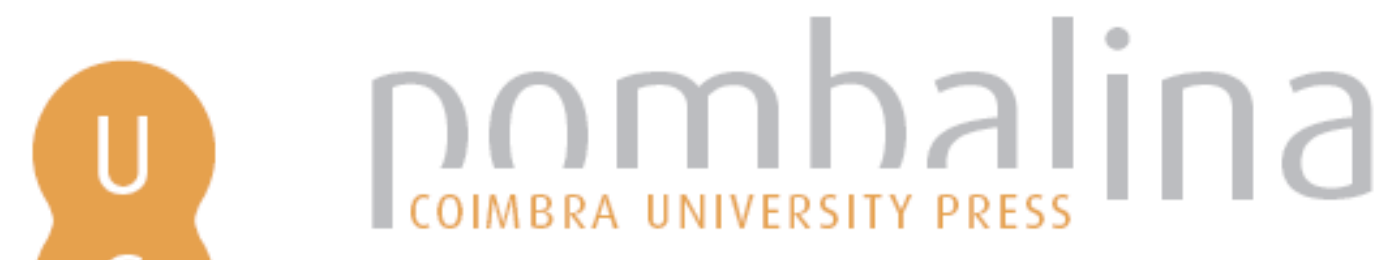

\title{
La Tradición Clásica en el Cine Mexicano (1963 - 1999)
}

Autor(es): $\quad$ Pianacci, Rómulo

Publicado por: Imprensa da Universidade de Coimbra

URL

persistente: URI:http://hdl.handle.net/10316.2/42962

DOI: $\quad$ DOI:https://doi.org/10.14195/978-989-26-1439-7_19

Accessed : $\quad$ 26-Apr-2023 15:45:10

A navegação consulta e descarregamento dos títulos inseridos nas Bibliotecas Digitais UC Digitalis, UC Pombalina e UC Impactum, pressupõem a aceitação plena e sem reservas dos Termos e Condições de Uso destas Bibliotecas Digitais, disponíveis em https://digitalis.uc.pt/pt-pt/termos.

Conforme exposto nos referidos Termos e Condições de Uso, o descarregamento de títulos de acesso restrito requer uma licença válida de autorização devendo o utilizador aceder ao(s) documento(s) a partir de um endereço de IP da instituição detentora da supramencionada licença.

Ao utilizador é apenas permitido o descarregamento para uso pessoal, pelo que o emprego do(s) título(s) descarregado(s) para outro fim, designadamente comercial, carece de autorização do respetivo autor ou editor da obra.

Na medida em que todas as obras da UC Digitalis se encontram protegidas pelo Código do Direito de Autor e Direitos Conexos e demais legislação aplicável, toda a cópia, parcial ou total, deste documento, nos casos em que é legalmente admitida, deverá conter ou fazer-se acompanhar por este aviso.

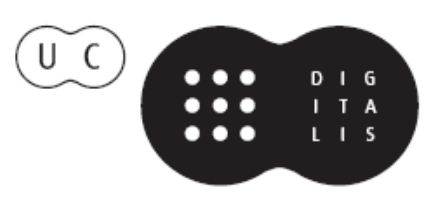




\section{Pervivencia del mundo clásico en la literatura:}

\section{tradición y relecturas}

\section{Aldo Rubén Pricco, Stella Maris Moro (coords.)}

IMPRENSA DA UNIVERSIDADE DE COIMBRA 


\title{
La Tradición Clásica en el Cine Mexicano (1963 - 1999) (Classical tradition in Mexican cinema (1963-1999))
}

\author{
Rómulo Pianacci (rpianacci@gmail.com) \\ UNMdP / UNCPBA
}

\begin{abstract}
Resumen - La presente comunicación forma parte del Proyecto de Investigación La persistencia de los modelos clásicos en América Latina: Literatura y Cine, que lleva ya varios años relevando una a una las dispersas producciones fílmicas latinoamericanas de contenido clásico grecolatino. Se analizarán tres transducciones de textos clásicos llevados a la pantalla mexicana: Las Troyanas (1963) de Sergio Véjar; La viuda (1965) con dirección de Benito Alazrak y finalmente Arturo Ripstein con su realización Así es la vida (1999) basada en la Medea de Séneca. Con diferente fortuna, los tres filmes reflejan la presencia de la Cultura Clásica en México, en todas sus particularidades, el especial su apego al melodrama, y no exentos de una cierta ironía en la pintura localista.
\end{abstract}

Palabras Clave: Literatura, cine, tradición clásica, México.

Abstract - The present communication is part of the research project Persistence of the classical models in Latin America: Literature and Cinema, which has taken several years in relieving one by one the scattered Latin American film productions on Greek classical content. Three transductions of classical texts brought to the Mexican screen will be analysed: the Las Troyanas (1963) by Sergio Véjar; La viuda by Benito Alazrak and finally Arturo Ripstein with his film Asi Es la Vida (1999) based on Seneca's Medea. With different fortune, these three films reflect the presence of classical culture in Mexico, in all its singularities, specially the attachment to melodrama, not exempt with a certain irony in the localist painting.

KeYwords: Literature, film, classical tradition, Mexico.

\section{CONTENido MELOdRAMÁtico o MELOdRAMA}

Según Pablo Pérez Rubio:

Su materia prima son los sentimientos, y en el aparecen abordados, al igual que en los mejores poemas petrarquistas y neoplatónicos, como la mayor fuente de placer y, a la vez, de dolor que atraviesa por la experiencia de vivir: el amor en todas sus variantes (incluido, por supuesto, el desamor), el sacrificio, la renuncia, el narcisismo, el envejecimiento, la infidelidad, la amistad, el temor a la muerte, la melancolía, la nostalgia, el dolor por una pérdida, la soledad, el reencuentro, la paternidad, la frustración y, sobre todo, el deseo. El melodrama describe los avatares de los sujetos deseantes inscritos en relatos caracterizados por el exceso y la desmesura, porque confieren toda su capacidad semántica a la conversión en texto narrativo (teatral, 
literario, cinematográfico, radiofónico, televisivo..., pero no poético) de estos sentimientos y la hacen reposar en personajes dolientes, ensimismados, maltratados. (Pérez Rubio 2004: 18)

La variación de estas categorías produciría un corpus tan variado de filmes, muy difícil de delimitar, ya que este "género de géneros" incluye: el melodrama familiar, el melodrama romántico, el melodrama materno, el melodrama de épo$\mathrm{ca}$, de la women's picture y el weepie, el tearjerker y el denigrado genre larmoyant. De aquí es que se hable preferentemente de un género transversal, que incluye títulos ya clásicos como: El nacimiento de una nación (The Birth of a Nation, 1915) de David W. Griffith; La mujer del puerto de Arcady Boytler (Ídem, 1931); La dama de las camelias (Camille, 1936) de George Cukor; Casablanca (Ídem, 1942) de Michael Curtiz; la producción de Nicholas Ray Johnny Guitar (Ídem, 1954); Escrito en el viento (Written on the Wind, 1956) de Douglas Sirk; Téy simpatia (Tea and Sympathy,1956) de Vincente Minnelli; Algo para recordar (Affair to Remember, 1957) de Leo McCarey y Hable con ella (Ídem, 2002) de Pedro Almodóvar, etc., etc., etc.

Según Pérez Rubio en las tragedias del ateniense Sófocles del s. V a.C. ya era frecuente que tanto algunos personajes, como el Coro, pronunciasen quejas y comentarios melancólicos sobre el dolor que producen la existencia y el destino $y$, por el contrario, la felicidad que gozan quienes no han nacido hombres: el carácter sufriente -paciente, podría decirse- de la condición humana.

En nuestro contexto, el cine de contenido melodramático argentino tiene mucho que agradecer su difusión internacional a directores como Luis César Amadori, Armando Bo, Lucas Demare, Luis Saslavsky, Leopoldo Torre Nilsson, Alberto de Zavalía, entre muchos; y a estrellas como Laura Hidalgo, Tita Merello, Zully Moreno, Mecha Ortiz y la reina indiscutida del melodrama y "La novia de América" Libertad Lamarque.

El melodrama, pues, adquiere ya en los primeros pasos del cine un carácter multiforme e intergenérico. Así, pues, para ser más rigurosos con su propio concepto, la amplia noción del género "melodrama" quizás debería dejar paso, en una primera instancia, a la idea de lo melodramático en el cine. (Pérez Rubio 2004: 30)

\section{Las Troyanas (1963) de Sergio VéJar}

Sergio Véjar nace en 1928 en la capital del estado de Colima (México), aunque a temprana edad se muda con su familia al D.F. Comenzó primero como iluminador, y después como operador de cámara y asistente de los más importantes fotógrafos del cine mexicano: Alex Phillips, Ezequiel Carrasco, Gabriel Figueroa, Agustín Jiménez, Víctor Herrera, Luis Márquez y Manuel Álvarez Bravo; y directores de gran renombre en la época como Juan Bustillo 
Oro, Julio Bracho, Alejandro Galindo, Gilberto Gazcón, Roberto Gavaldón, Juan Orol y Luis Buñuel, entre otros.

En 1953 Véjar debuta como director y guionista escribiendo y dirigiendo el cortometraje experimental San se acabó, galardonado en el Primer Concurso Experimental de Cortometrajes. Por otra parte, en 1960 viaja a Cuba para trabajar como director de fotografía de las películas Cuba baila de Julio García Espinosa e Historias de la revolución de Tomás Gutiérrez Alea, siendo estas las dos primeras películas realizadas por el recién creado ICAIC.

De vuelta a México, en 1962 Véjar filma Los signos del Zodiaco, con adaptación de Emilio Carballido sobre la pieza homónima de Sergio Magaña. Esta película sería su primer largometraje comercial y obtuvo el premio de mejor dirección en el Festival Cinematográfico de Moscú (1962). Irónicamente, poco antes del estreno comercial del filme, en 1964, el gobierno de Gustavo Díaz Ordaz la censuró y tuvieron que ser eliminados 35 minutos de la película para poder ser exhibida.

Otras películas en su filmografía son: Solo de noche vienes (1966), Cuatro contra el crimen (1968), El último pistolero (1969), La trenza (1975), Las mariposas disecadas (1978), La casa del pelícano (1978), Mamá, soy Paquito (1981), Coqueta (1984), La jaula de oro (1987), La puerta negra (1988), Traición (1991) y El ganador (1992). En su gran mayoría, el cine de Sergio Véjar es caracterizado por tratar temáticas de contenido social. Falleció el 15 de febrero de 2009 en Ciudad de México, víctima de un ataque al corazón, a los 80 años de edad.

Su versión de Las Troyanas respeta al pie de la letra el texto de Eurípides, traducido por Ángel M. Garibay K. Cuenta con la dirección teatral del Mtro. José Sole y la interpretación en los roles principales de Ofelia Guilman, Carmen Montejo y Enrique Lizalde, de evidente extracción teatral y en un estilo declamatorio más próximo al melodrama que a la tragedia. Filmada íntegramente en los Estudios San Ángel Inn, recrea la puesta teatral estrenada en marzo del mismo año en el Teatro Xola, del D.F. Todo el filme está resuelto en un solo escenario, diseñado por Julio Prieto, con el uso de varias cámaras, ángulos diferentes y planos secuencia que dan más dinamismo al planteo frontal del teatro a la italiana. En exteriores solo se rodó la secuencia inicial -el agón entre Palas Atenea y Poseidón- estando sobreimpreso sobre la rompiente de un mar embravecido. El vestuario recurre a similitudes con la ropa campesina mexicana con sarapes y mantas, en tonos de gris y negro, reforzados por la fotografía en blanco y negro de Agustín Jiménez.

\section{La VIUda (1965) DE Benito AlazraK}

Este episodio forma parte de la trilogía de relatos incluidos en el filme Amor, amor, amor... (1965). Los otros dos son: La Sunamita dirigido por 
Héctor Mendoza, con la actuación protagónica de Max Aub, crítico y autor franco-valenciano refugiado en México; y Lola de mi vida dirigido por Miguel Barbachano Ponce y guión de Gabriel García Márquez. Un cuarto episodio, Las dos Elenas, fue eliminado para el estreno.

Según el relato de Petronio, había una vez en Éfeso una dama de tan celebrada virtud, que las mujeres de las ciudades vecinas viajaban grandes distancias para verla y expresarle su admiración. Al morir su esposo no se contentó con tirarse de los cabellos, golpearse el pecho, y ejecutar todas las habituales manifestaciones de dolor, sino que insistió en seguir su cuerpo hasta la misma tumba, al lado de la cual se mantuvo en vigilia noche y de día. Tal era su devoción por el desaparecido que durante cinco días enteros y otras tantas noches mantuvo el ayuno. Hombres y mujeres de todos los oficios, de todos los temperamentos coincidieron en que aquella mujer era en verdad un dechado de virtudes, de verdadero amor y de castidad sin par.

Coincidiendo con estos hechos una banda de criminales fue encontrada culpable de delitos que merecían la pena capital, y se los sentenció a ser crucificados cerca de la tumba donde la viuda lloraba sobre el cuerpo de su esposo. La sentencia se llevó a cabo al quinto día, y aquella noche se dejó allí un soldado de guardia, por temor a que los amigos o parientes de los condenados se apoderaran de los cadáveres para enterrarlos.

Mientras montaba guardia, el soldado vio una luz en la tumba, y oyó el llanto de la afligida mujer. Se dirigió al lugar para investigar lo que pasaba, y vio a aquella dama, cuya belleza no habían agotado las lágrimas, sino por el contrario, la habían realzado.

Hablando en voz baja, el soldado trató de consolarla, diciéndole que todos los hombres tienen que morir y que el dolor de los vivientes no le sirve de nada a los muertos ni a nadie. Al oírle expresarse así se iluminó el semblante de la mujer y su rostro cobró nueva vida. Tuvo que convenir en que su comportamiento era en verdad, insensato, y entonces el soldado corrió en busca de su morral para extraer la comida que llevaba para él, compartiéndola con la viuda.

Mientras cenaba, y con ello recuperaba sus fuerzas, la mujer pudo advertir que su interlocutor era muy atractivo. Apercibido de ello el soldado, se dirigió a la dama en los términos en que lo hacen los amantes, con halagos parecidos a aquellos con los que consiguió persuadirla de que debía amar la vida. Completamente cautivada por el, la mujer no pudo negarle nada, y en consecuencia se rindió a sus abrazos, y allí mismo, sobre el suelo y cerca del cuerpo del esposo.

No solo aquella noche se entregaron al escarceo amoroso, sino también la siguiente y una tercera. El soldado se enamoró de tal manera, que permaneció junto a ella durante todo el tiempo que debía destinar al cumplimiento de sus deberes.

Sucedió que una noche los parientes de uno de los criminales crucificados visitaron el lugar de la ejecución, y al ver que el cuerpo de su ser querido no 
estaba vigilado, lo bajaron de la cruz para darle sepultura.

Cuando al día siguiente el soldado se dio cuenta de la pérdida, quedó aterrado. Las ordenanzas militares castigaban con la crucifixión al que abandonara la guardia en tales circunstancias.

Irrumpiendo en el interior de la tumba, instó a su amante a que le hundiera la espada en el cuerpo, y le enterrara luego junto al cadáver de su esposo. La dama, sin embargo, no quiso escucharlo.

-Ya he perdido un hombre- repuso ella. -Sufrir la pérdida de un segundo sería algo que no podría soportar. Lo que debemos hacer es colgar en la cruz el cadáver de mi esposo, en lugar del cuerpo robado. Tus superiores nunca advertirán la suplantación, y nosotros quedaremos en libertad de reanudar nuestros amores sin interrupción.

El soldado acuerda en ello, e inmediatamente tomó el cuerpo del difunto marido para clavarlo en la cruz. Y desde aquel momento la dama y el soldado vivieron felices como amantes.

El guión de La viuda sigue los lineamientos generales del relato petroniano, pero ambientándolo en un típico cementerio del México durante el período revolucionario. Ernestina Robredo interpreta a Leonor Lobato, la viuda, y Héctor Godoy es el soldado Juan Patiño del ejército regular, encargado de vigilar el cadáver de un revolucionario recientemente ejecutado. Luego de desarrollar la trama amorosa y una vez que se retiran los amantes, los generales superiores del soldado elogian a esta dama como espejo de las virtudes tradicionales de la mujer mexicana, en un final no exento de cierta ironía y de la moralina que podría desprenderse del texto de Petronio que finaliza poniendo en boca de Licas: "Si el gobernador hubiera sabido hacer justicia, tenía que haber devuelto a su tumba el cadáver de ese padre de familia y crucificado a la mujer en su lugar." (Petronio, 158)

Benito Alazrak (México, 1923) es licenciado en Derecho y Filosofía y Letras. Colaboró como guionista y productor de Emilio Fernández y Carlos Velo. Residió diez años en España (1962-1972) trabajando para la TV y realizando dos coproducciones con México: Los jóvenes amantes y Las tres perfectas casadas. Vuelto a México, su producción se ubica entre el documental etnográfico, el neorrealismo italiano y las aportaciones de Buñuel, constituyéndose en una experiencia insólita en el marco del cine mexicano de la época. Su filme Raíces (1953), ejemplo del característico cine indigenista, es considerado un lúcido manifiesto sobre el tema de la miseria en México y un desafío al cine comercial puramente escapista dominante en el momento. Abandonando las ambiciones de su opera prima, abordará posteriormente géneros más populares: aventuras, terror, melodrama, etc. Entre sus más de cuarenta filmes, el más apreciado generalmente es su Café Colón (1958), musical ambientado durante la Revolución Mexicana e interpretado por María Félix y Pedro Armendáriz. 


\section{Así es LA VidA... (1999) de Arturo Ripstein}

Confluyen en la elaboración de Así es la vida... varias cuestiones que se deben tener en consideración. Por un lado, la tradición cinematográfica mexicana con directores que han aportado su mirada personal al melodrama, "con formas de expresión a partir de un molde siempre flexible, como es el caso del Indio Fernández, Arturo Ripstein y Luis Buñuel desde México, Ozu y Mizoguchi desde Japón, Fassinder desde Alemania, Kaurismäki desde Finlandia o Almodóvar desde España." (Pérez Rubio 2004: 17)

Por otro lado, emerge la personalidad del director, de cuyo cine Santos Zunzunegui ha dicho: "alcanza la dimensión de un mundo 'autocontenido' que muestra, mediante el espejo deformante del melodrama, lo sórdido y lo grotesco que incuba la vulgaridad de nuestras vidas." (Kriger-Portela 1997: 408)

Según Ripstein y su guionista Paz Alicia Garciadiego, la bárbara maga se transforma en Julia, una curandera, posiblemente migrante al D. F., que como en el caso del personaje mítico es abandonada por Nicolás, el boxeador Nicolás, a quien ella ha dedicado su vida. Desalojada por su casero, "La Marrana", cuya hija Raquel está por casarse con su marido, y pese a los sabios consejos de su madrina, desata así la tragedia de su venganza inmolando a sus hijos, en este caso una hembrita y un varón. Abandona luego la miserable vecindad, abordando un reluciente taxi Volkswagen pintado de un brillante amarillo rabioso.

La escritura de Garciadiego respeta, en términos generales, la estructura de la Medea de Séneca, y la transduce a un mundo reconstruido con un lenguaje de situaciones cotidianas del mundo marginal de una vecindad. Julia atiende en su dispensario de medicina informal a sus "pacientes" pero debido a su origen "de extranjera" y las prácticas que realiza, es a la vez respetada, temida y despreciada. En sus desesperados monólogos no solo describe su situación de mujer abandonada sino que pinta la realidad de la resignada mujer mexicana en general, víctima del machismo y la violencia generalizada. Ante la adversidad solo puede decir: "Así es la vida...”; y frente al abandono sufrido, solo puede comentar resignadamente: "Se me acabó el mundo".

El personaje de la nodriza, transformado en "la madrina" de Julia, tiene una mayor presencia escénica, y en un monólogo frente a un feto que guarda en un frasco, "lo único verdaderamente mío", señala amargamente: "El macho, capado o muerto". Finalmente ella también abandonará a Julia, luego de intentar en vano convencerla de no cometer alguna locura; pero el relato de sus propias miserias apuntala, sin quererlo, la decisión de Julia.

Nicolás / Jasón asume todas las características del estereotipo del macho mexicano, con una mediocre carrera como boxeador, ve egoístamente en Raquel no solo la belleza de la juventud sino también una ventaja económica para el y sus hijos. En su monólogo en off, mientras entrena en el gimnasio, asume su sola voluntad como único válido parámetro. 
El Coro aparece transpuesto en un trío de viejos mariachis, cantantes de boleros -Anselmo Fuentes y sus muchachos- con un joven imberbe que en primer plano malamente toca las maracas. Sus canciones subrayan y comentan los acontecimientos, ya sea desde su presencia "real" o desde la imagen de un viejo televisor en blanco y negro. Este objeto aparece reiteradamente, emitiendo los pronósticos del tiempo, escenas de sexo entre Nicolás y Raquel, noticias de desastres naturales o policiales. Así aparece filmada la muerte de La Marrana y su hija, en un incendio en su vivienda, y el reportero incluso entrevista a Julia y su madrina. Pero luego los vemos nuevamente preparando la boda, por lo que quizás su muerte sea nada más que la proyección del deseo de Julia, o de su mundo mágico como en la Medea de Pasolini.

El efecto de distanciamiento está logrado mediante varios procedimientos formales: la constante cámara en mano -de lectura casi periodística- que persigue a los actores por la miserable vivienda, la mirada fija de estos directamente a la cámara en muchos momentos o la visión del equipo de filmación al voltearse "casualmente" un espejo. El personaje de Julia, al momento de dar muerte a sus hijos, le cierra la puerta en las narices a la cámara, restaurando la estética de la abstinencia de la escena trágica. Una vez consumado el crimen le dice a Nicolás: "Mira lo que me, lo que has, lo que he, lo que hemos hecho", en una lectura mucho más abarcadora de las responsabilidades del hecho.

Finalmente, Ripstein reinstala la dimensión mítica del relato incluyendo en varias secuencias la visión posterior de una camioneta de brillante metal, desplazándose a toda velocidad por las calles de la ciudad al compás de una música de feria y reflejando la luz dorada de miles de lamparitas.

\section{A MODO DE CIERRE}

Y es que los ecos de la tragedia griega, tan ligada a los destinos de la polis (léase ahora sociedad, sociedades), están muy presentes en el melodrama; hasta tal punto es así que en no pocas ocasiones esas heridas son colectivas y las consiguientes catarsis afectan igualmente a todo el tejido social. (Pérez Rubio 2004: 15)

Estos tres ejemplos permiten ver que en el abordaje de una transducción literatura / filme aparecerían modulaciones varias y se puede reconocer la migración hacia mundos paralelos, complementarios o incluso polémicos. En el inventario de agentes se admiten variaciones de personajes que con la misma etiqueta semántica de una obra a la otra son replicados, elididos o adicionados en un doble juego de espejos que multiplican ad infinitum no solo el contenido sino también en las formas a las que recurren estos creadores para seguir cautivando a los espectadores contemporáneos. Renuevan así, a su manera, la antigua magia de contar historias ejemplares. 


\section{BibLIOGRAFía}

Kriger, C., Portela, A. (1997), Diccionario de realizadores. Buenos Aires: Ediciones del Jilguero.

Pérez Rubio, P. (2004), El cine melodramático. Barcelona: Paidós Ibérica, S. A. Petronio (1995), El Satiricón, Trad. Rubio Fernández, L. Barcelona: Editorial Planeta-De Agostini, S.A. 